Provided for non-commercial research and education use. Not for reproduction, distribution or commercial use.

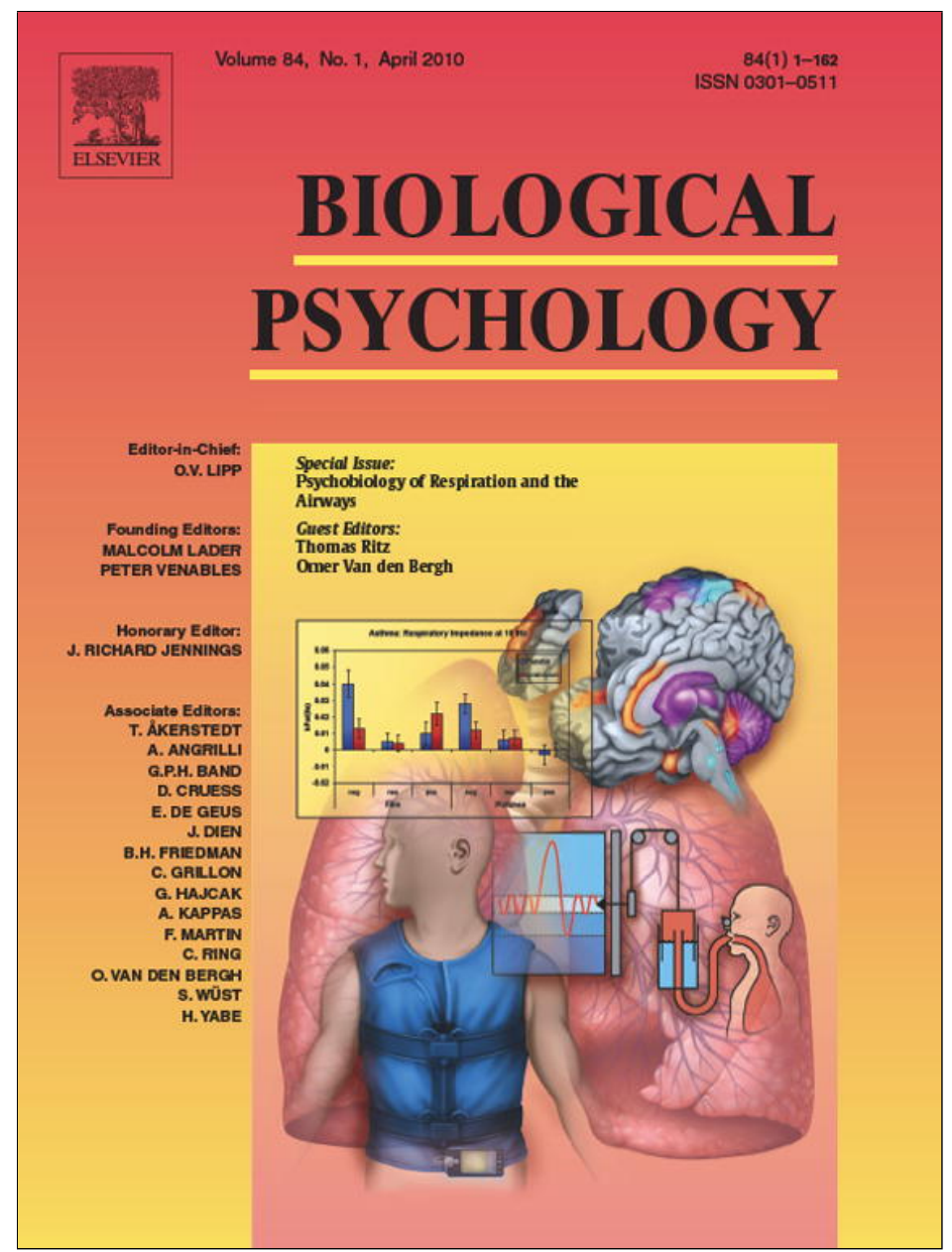

This article appeared in a journal published by Elsevier. The attached copy is furnished to the author for internal non-commercial research and education use, including for instruction at the authors institution and sharing with colleagues.

Other uses, including reproduction and distribution, or selling or licensing copies, or posting to personal, institutional or third party websites are prohibited.

In most cases authors are permitted to post their version of the article (e.g. in Word or Tex form) to their personal website or institutional repository. Authors requiring further information regarding Elsevier's archiving and manuscript policies are encouraged to visit:

http://www.elsevier.com/copyright 


\title{
Defense reactions to interoceptive threats: A comparison between loaded breathing and aversive picture viewing
}

\author{
Meike Pappens ${ }^{\mathrm{a}}$, Omer Van den Bergh ${ }^{\mathrm{a}}$, Steven De Peuter ${ }^{\mathrm{a}}$, Johan Bresseleers ${ }^{\mathrm{a}}$, \\ Debora Vansteenwegen ${ }^{\mathrm{b}}$, Ilse Van Diest $^{\mathrm{a}, *}$ \\ ${ }^{a}$ Research Group on Health Psychology, Department of Psychology, University of Leuven, Tiensestraat 102, 3000 Leuven, Belgium \\ ${ }^{\mathrm{b}}$ Center for the Psychology of Learning and Experimental Psychopathology, Department of Psychology, University of Leuven, Belgium
}

\section{A R T I C L E I N F O}

\section{Article history:}

Received 7 May 2009

Accepted 11 February 2010

Available online 19 February 2010

\section{Keywords:}

Interoception

Fear

Psychophysiology

Loaded breathing

\begin{abstract}
A B S T R A C T
Human fear research has mostly applied exteroceptive stimuli to induce fear. Interoceptive sensations however can also be very threatening and play a major role in a number of anxiety disorders. In this study, we compared affective responses to inspiratory resistive loads with those to aversive pictures. During repeated administrations of two loads, a light and a moderate one, and five aversive pictures we measured electrodermal activity, startle blink responses, subjective fear and ratings on valence, arousal and dominance. Results indicate that loads evoke affective reactions comparable or stronger than those evoked by the pictures. Startle data did not follow this pattern with an absence of startle potentiation during the moderate load, suggesting that fear potentiated startle does not occur when the background aversive stimulus is of an interoceptive nature.
\end{abstract}

(C) 2010 Elsevier B.V. All rights reserved.
Human fear responses can be reliably identified on the basis of peripheral physiological and somatic responses to a standardized set of aversive stimuli (Lang et al., 2000). Heart rate changes, the skin conductance response (SCR) and a fear potentiated startle reflex are reactions regulated by subcortical and deep cortical brain structures such as the amygdala and the areas it projects to. Since these structures are neuro-anatomically and functionally similar across mammalian species, Lang et al. (1997) adopted a well-validated animal model (Blanchard and Blanchard, 1989; Fanselow, 1994; Gray and McNaughton, 2000) to explain human defensive responses. The 'defense cascade model' describes fear reactions along an 'arousal' continuum with arousal level being influenced by features of the threatening stimulus and aspects of the situation in which the danger is encountered (Blanchard et al., 2001; Lang et al., 1997). The continuum starts at a pre-encounter 'calm' state where the possibility of threat is present, but no specific danger has yet been noticed. This stage is followed by a postencounter 'alert' phase in which an actual threat has been perceived and the magnitude of the danger is being monitored. 'Freezing' behavior is commonly observed in this stadium with the organism being immobilized, hypervigilant and primed to undertake action. The end of the continuum is characterized by massive bursts of autonomic arousal in a circa-strike context where the inevitability of a dangerous encounter with the threat has become clear and one engages in an active fight or flight reaction. According to the defense

\footnotetext{
* Corresponding author. Tel.: +32 163260 29; fax: +32 16326055

E-mail address: ilse.vandiest@psy.kuleuven.be (I. Van Diest).
}

cascade model, SCR rises along the continuum because it covaries with arousal level (Bradley et al., 2001). Heart rate decelerates in the orienting phase and accelerates once an organism prepares for action. The eye blink startle reflex is modulated by sequential and sometimes concurrent sensory, attentional and affective processes, with reflex magnitude reflecting the net effect of these multiple influences (Bradley et al., 2006). When the reflex evoking probe is released shortly ( $50-300 \mathrm{~ms})$ after the administration of a non-startling stimulus (a prepulse), sensory-gating and attentional mechanisms dominate the modulation of the eye blink reflex often resulting in 'prepulse inhibition' (PPI), a suppressed startle response. Once the prepulse is encoded, the eye blink reflex is affectively modulated by the content of the prepulse, with potentiated responses for negative stimuli and reduced startle responses for positive events (Bradley et al., 1999). In phobics, differentiation between a fear state and a neutral state on the basis of eye blink responding is present already at $300 \mathrm{~ms}$ after stimulus onset (Globisch et al., 1999). In healthy persons, affective startle modulation seems to appear only at $1300 \mathrm{~ms}$ (Bradley et al., 1993), although other evidence did show modulation at shorter lead intervals (Volz et al., 2003).

Human defensive reactions in the laboratory have mainly been studied in response to exteroceptive aversive stimuli, such as photographic material of the International Affective Picture System database (IAPS; Center for the Study of Emotion and Attention, 1999), unpleasant sounds, imagery scripts, or external warning signals that announce an aversive event (e.g., Hamm and Vaitl, 1996; Neumann et al., 2008; Cook et al., 1988; Grillon et al., 1991). For the majority of anxiety disorders such as specific phobias, social 
phobia and PTSD, external threats are indeed very relevant. However, a number of psychiatric disorders and somatic diseases may benefit from a systematic study of defensive responses to interoceptive aversive stimulation. For example, patients with asthma often fear the sensation of breathlessness (dyspnea), because it may be a predictor of a severe, possibly fatal asthma attack. Also in panic disorder, interoceptive sensations are thought to play an important role (Bouton et al., 2001) and exposure to interoceptive events has been proposed and implemented as a therapeutic tool to reduce complaints in panic disorder (Craske et al., 1997; Beck et al., 1997; Smits et al., 2007; Esquivel et al., 2008).

The bodily sensations that panic disorder patients typically fear (e.g. shortness of breath, warmth, a racing heart) can be induced in the laboratory by administration of carbon dioxide $\left(\mathrm{CO}_{2}\right)$-enriched air (e.g., Acheson et al., 2007; Fannes et al., 2008; Forsyth et al., 1996; Sanderson et al., 1988). Unfortunately, the parameters of this interoceptive stimulus are difficult to control: stimulus intensity, onset and offset depend in part on the respiratory behavior of the participant and the dead space in the breathing circuit, causing a variable delay in the amount and the time at which the $\mathrm{CO}_{2}$ reaches the participant (Fannes et al., 2008). Another difficulty is that the effects of $\mathrm{CO}_{2}$-inhalation (increases in ventilation and general arousal) appear only gradually and need a relatively long time.

Whereas $\mathrm{CO}_{2}$-inhalation is a chemical stimulus acting upon central, and to a lesser extent also upon peripheral chemoreceptors, adding extrinsic mechanical loads to the breathing circuit acts primarily upon mechanoreceptors. When a mechanical load is present, the respiratory muscles must work harder to ventilate the lungs, inducing a subjective feeling of dyspnea which is often also described as a feeling of "increased effort". Inspiratory resistive loads have been used extensively in the literature on load magnitude estimation as a laboratory model for blunted perception of bronchoconstriction in asthma patients (e.g., Webster and Colrain, 2000; Bloch-Salisbury and Harver, 1994). Interest in affective responses to resistive loads has risen only lately. This is surprising, given that few sensations call more for immediate defensive action than an acute limitation to breathe. In one study (Van Diest et al., 2005a), it was found that an inspiratory load of $1.47 \mathrm{kPal}^{-1} \mathrm{~s}$ elicited more breathlessness and fear, and was evaluated as more aversive than a $20 \mathrm{~s}$ inhalation of $20 \%-\mathrm{CO}_{2}$-enriched air. A few studies have documented that interindividual differences in anxiety or depression are predictive for subjective responses to inspiratory loads, but not for the ventilatory responses to them (Lavietes et al., 2000; Livermore et al., 2008). Subjective unpleasantness of inspiratory loads is associated with activation of the anterior insula and the amygdala (von Leupoldt et al., 2008), but the peripheral fear response topography to inspiratory loads has not been described yet.

It is likely that the lack of a standardized set of interoceptive stimuli that can be easily applied and controlled in the laboratory has hampered the development of theory and research on human interoceptive fear. A first important step is to systematically describe the fear response topography to interoceptive threats and compare it with defense reactions to exteroceptive threats. Some findings point to potentially important differences. For example, when imagining their (external) object of fear, phobic patients display increased skin conductance responses, more heart rate acceleration and an enhanced startle blink response compared to neutral imagery. In contrast, panic patients do not show these elevated reactions when imagining their feared interoceptive sensations (Cuthbert et al., 2003). Also, Van Diest et al. (2005b) found that (imagined) risk of suffocation is associated with a more pronounced ventilatory increase than other (imagined) external threats that evoked equal levels of subjective fear. Compared to students, this effect was even more pronounced in patients with medically unexplained dyspnea from whom $1 / 3$ qualified for a diagnosis of panic disorder (Han et al., 2008).

To explore this issue further and to test whether the defense cascade model is also applicable to interoceptive threats, the present study aimed to study fear responses to dyspneic stimuli as induced with inspiratory resistive loads and to compare them with responses to aversive IAPS pictures.

Participants received repeatedly two loads of a different intensity and five threatening IAPS pictures, while the acoustic startle reflex, SCR and subjective fear scales were being assessed.

Based on the defense cascade model (Lang et al., 2000) and on previous findings regarding PPI (Bradley et al., 2001), the following predictions were formulated. (1) Compared to the light load, the moderate load will be associated with stronger SCRs, stronger subjective fear and increased startle responses when probing at 1500 ms after stimulus onset. (2) Compared to the no stimulus conditions, increased startle responses will occur for the light load, the moderate load and the pictures when probing at $1500 \mathrm{~ms}$ after stimulus onset. Because the literature does not allow for strong predictions regarding affective startle modulation at short lead intervals, we do not formulate any particular prediction for the $500 \mathrm{~ms}$ lead interval; startle responsivity in these conditions will be explored.

\section{Methods}

\subsection{Participants}

Forty-one university students ( 24 women, $M=19.5$ years, range $18-22$ years) participated in this study in return for course credit. Participants were only allowed to participate if they confirmed not to smoke more than 10 cigarettes per day; not to suffer from any respiratory or cardiac disease, epilepsy, or psychiatric disorder; if they were not pregnant and had no signs of any current minor or major illness.

Because of equipment problems, the data from two participants were excluded from the SCR and the EMG analyses. The data of another participant was not used because he dropped out during the experiment. All subjects provided an informed consent. The experiment was approved by the Ethics Committees of the Department of Psychology and of the Faculty of Medical Sciences.

\subsection{Materials}

Pictures. Five fear-inducing images from the International Affective Picture System (IAPS; Center for the Study of Emotion and Attention, 1999) were selected because of their high scores on the fear factor (Mikels et al., 2005). They depicted a snake (1052), an aggressive dog (1302), a shark (1930), a masked man (6370) and a sinking boat (9600).

Loads. Two linear Hans Rudolph loads were used: one of $0.49 \mathrm{kPa} \mathrm{l}^{-1} \mathrm{~s}$ and one of $1.96 \mathrm{kPa} \mathrm{l}^{-1} \mathrm{~s}$. The former load can be considered as 'light' because the resistive effect lies just above the perceptual threshold (Bloch-Salisbury et al., 1998). The latter is 'moderate' compared to loads used in other studies (e.g. von Leupoldt et al., 2007).

Breathing apparatus. Participants breathed through a mouthpiece and wore a noseclip. The mouthpiece was connected to a microbial filter (MicroGard, VIASYS) mounted on a heated pneumotachograph (Fleisch no. 2, Epalinges, Switzerland), an instrument measuring airflow. The pneumotachograph was connected to a nonrebreathing valve ensuring the separation of inspiratory and expiratory air. A vinyl tube (inner diameter: $3.5 \mathrm{~cm}$; length $100 \mathrm{~cm}$ ) connected the inspiratory side of the non-rebreathing valve with a 3-way Y-valve (stopcock type) enabling easy switching between loaded (with load) and unloaded breathing (without load).

Both the signals from the sidestream infrared $\mathrm{CO}_{2}$-monitor (Poet II, Criticare, Waukesha, WI), and from the pressure transducer (Sine Wave Carier Demodulator $\mathrm{CD} 15$, Valydine Engineering ${ }^{\mathrm{TM}}$ ) were sampled at $50 \mathrm{~Hz}$ and were daily calibrated using a $1 \mathrm{~L}$ syringe and a $7.5 \% \mathrm{CO}_{2}$ mixture, respectively. $\mathrm{CO}_{2}$ was sampled close to the mouthpiece.

EMG startle response. The eyeblink startle response was measured by recording surface EMG activity over the $\mathrm{m}$. orbicularis oculi just beneath the left eye, using three $\mathrm{Ag} / \mathrm{AgCl}$ Sensormedics electrodes $(0.25 \mathrm{~cm}$ diameter) filled with electrolyte gel. After cleaning the skin with peeling cream to reduce the inter-electrode resistance, electrodes were placed on the left side of the face according to the site specifications proposed by Blumenthal et al. (2005). The raw signal was amplified by a Coulbourn isolated bioamplifier with bandpass filter (v75-04) and routed to a Coulbourn contour-following integrator (S76-01) which rectified and smoothed the signal (time constant $=50 \mathrm{~ms}$ ). The recording bandwith of the EMG signal was $23 \mathrm{~Hz}-10 \mathrm{kHz}$. The EMG signal was transmitted through a labmaster card (12 AD converter) to a personal computer. During the $500 \mathrm{~ms}$ before the onset of white 
noise until $1000 \mathrm{~ms}$ after onset of white noise, the EMG signal was sampled and stored at $1000 \mathrm{~Hz}$.

Skin conductance. Electrodermal activity was recorded with Fukuda standard $\mathrm{Ag} / \mathrm{AgCl}$ electrodes ( $1 \mathrm{~cm}$ diameter) filled with $\mathrm{KY}$ gel and attached to the hypothenar palm of the left hand, which was first cleaned with tap water. The inter-electrode distance was $2.5 \mathrm{~cm}$. The Coulbourn skin conductance coupler (V71-23) provided a constant $0.5 \mathrm{~V}$ across the electrodes. The analogue signal was passed through a 12-bit AD converter and digitized at $10 \mathrm{~Hz}$.

Software. The airflow, end-tidal $\mathrm{CO}_{2}$, EMG and the skin conductance signals were recorded using Affect 4.0 software (Hermans et al., 2005). The signals were treated off-line with PSychoPHysiological Analysis (PSPHA - De Clerck et al., 2006), a modular script-based program which we further developed to generate and apply calibration factors for each signal. All waveforms were visually inspected off-line and technical abnormalities and movement artifacts were eliminated using the PSPHA software. Parameter extraction (see later) from each signal was also performed by PSPHA.

Self-report measures. After each stimulus presentation, participants rated thei fear on an online computerized VAS-scale $(0$, not at all scared - 100, extremely scared). Following the experiment the participant had to choose which picture he/she found most aversive. The language-free Self-Assessment Manikin (SAMScale, Bradley and Lang, 1994) was then administered retrospectively to evaluate the participant's response to the light load, the moderate load and the most aversive picture. With the SAM-Scale it is possible to measure the emotional state of subjects on three pictographic dimensions: valence, arousal and dominance. We administered a 5 -step SAM-scale (1-5), leaving out the ratings between the pictograms. The valence scale rated how pleasant (1) or unpleasant (5) participants felt during the stimuli. The arousal scale measured how calm (1) or excited (5) participants felt during the stimuli and the dominance scale assessed whether participants felt in (5) or out (1) of control during the stimuli.

\subsection{Procedure}

Participants were seated in a comfortable chair in front of a computer monitor. They read an information sheet explaining the purpose of the study and the stimuli and measures used and subsequently signed the informed consent form. After attachment of the electrodes, participants were instructed to breathe through a mouthpiece with the noseclip on. They were instructed to move as little as possible during the experiment in order not to disturb the measurements. We demonstrated how to use the online fear scale and asked them to leave their hand close to the fear scale button during the whole experiment. We informed them that they could stop their participation at each moment during the experiment.

Before starting the experiment we administered ten acoustic startle probes in a habituation phase with $30 \mathrm{~s}$ intertrial intervals (ITI). The habituation phase was followed by a $2 \mathrm{~min}$ baseline measurement. The experiment itself consisted of 60 trials with 30 s ITI's.

The following stimuli were presented in a randomized order: three times each of the five threat pictures from the IAPS, 15 times a load of $0.49 \mathrm{kPal}^{-1} \mathrm{~s}$ and 15 times a load of $1.96 \mathrm{kPal}^{-1} \mathrm{~s}$. The pictures were presented for $8 \mathrm{~s}$ and the loads were administered for one full inspiration. A within-individual control condition withou stimulus (neither inspiratory load, neither picture) was administered 15 times as well, allowing to investigate whether the experimental stimuli (flow resistors and fear pictures) evoke unpleasant feelings in addition to those related to experimental context (e.g., breathing through a mouth piece).

The breathing cycle was monitored online by Affect 4.0. Loads were manually turned on and off at the inspiratory side of the non-rebreathing valve during the expiratory phase prior and following the targeted inspiration. As a consequence, participants could sense the load application at inspiratory onset. Also the pictures were presented around inspiratory onset. When the respiratory flow reversed from expiration to inspiration, the experimenter manually triggered the presentation of the picture (in the picture condition) by pressing the space bar on a computer. Also the timing of the startle probe lead interval was started upon this manual signal from the experimenter. An acoustic startle probe (an instantaneous binaural $95 \mathrm{~dB}$ white noise probe of $50 \mathrm{~ms}$ ) was administered through the headphones in two thirds of the trials. Half of the acoustic startle probes were presented at $500 \mathrm{~ms}$ following the (manually signaled) start of inspiration; the other half were presented at $1500 \mathrm{~ms}$ after the inspiratory onset - signal. ${ }^{1}$ In one third of the trials no startle probe was administered. The light load, the moderate load and the no stimulus condition were administered five times in each of the three probe conditions. Each of the five IAPS pictures was presented once in each probe condition.

\footnotetext{
1 The manual starting of the startle probe lead interval upon inspiratory onset may have caused some jitter in the timing of the startle probes. However, given the knowledge that in healthy persons, affective modulation of the startle reflex is unlikely when probing $1300 \mathrm{~ms}$ after stimulus onset (Globisch et al., 1999), this jitter does not pose a major problem for the testing of our main hypotheses regarding startle, being that we expect affective modulation when probing around $1500 \mathrm{~ms}$
} after stimulus onset, but not when probing around $500 \mathrm{~ms}$
Skin conductance, startle blink responses and airflow were registered. Following each trial the participant rated how much fear he/she had experienced during the stimulus presentation on a VAS-scale that appeared on the monitor. At the end of the experiment the participant had to choose retrospectively which picture he/she found most aversive and then filled out a SAM-scale for the most threatening picture the moderate and the light load.

\subsection{Data reduction and statistical analysis}

Electrodermal parameter extraction. Electrodermal responses were calculated by subtracting the mean skin conductance level (SCL) during $1 \mathrm{~s}$ prior to stimulus onset from the maximum SCL during $4 \mathrm{~s}$ following stimulus (pictures or loads) onset. The data were $\log$ transformed $[\log (\mathrm{SCR}+1)]$ in order to obtain a normal distribution. Only data from trials without acoustic startle probes were included in the analyses of electrodermal responses.

Eye blink parameter extraction. Startle blink responses were calculated by taking the difference between the peak value in the $21-175 \mathrm{~ms}$ time window and the mean value from the 0-20 time window following probe onset. For each probe condition $(500 \mathrm{~ms} / 1500 \mathrm{~ms})$, mean EMG responses per stimulus across presentations were calculated for each person. These responses were then T-transformed within persons. Only the data of participants showing a startle blink in more than $30 \%$ of the trials were included, resulting in $N=27$ for the analyses on the startle data. ${ }^{2}$

Respiratory parameters extraction. Inspiratory time $\left(T_{\mathrm{I}}\right.$, in $\left.\mathrm{s}\right)$, expiratory time $\left(T_{\mathrm{E}}\right.$, in $\mathrm{s})$, tidal volume $\left(V_{\mathrm{T}}\right.$, in $\left.\mathrm{ml}\right)$, minute ventilation $\left(V_{\mathrm{E}}^{\prime}\right)$ and fractional end-tidal $\mathrm{CO}_{2}$ $\left(\mathrm{F}_{\mathrm{et}} \mathrm{CO}_{2}\right)$ were calculated for each first breath during each stimulus application for every trial.

Statistical analyses. Electrodermal and subjective fear responses were analyzed in a Repeated Measures ANOVA (RM ANOVA) with 'stimulus' (picture, light load, moderate load, no stimulus) and 'block' (5 levels for SCR; 15 levels for subjective fear) as within subject variables.

Startle magnitudes and respiratory parameters were analyzed in a RM ANOVA with 'stimulus' (picture, light load, moderate load, no stimulus) as a within subject variable.

A RM ANOVA with 'stimulus' (most aversive picture, light load, moderate load) as within subject variable was performed on the pleasantness, arousal and dominance ratings (SAM-scales).

Tukey HSD tests were used for post hoc comparisons. Statistical significance was accepted at the $p<.05$ level (2-tailed). Greenhouse-Geisser corrections were applied where appropriate. Uncorrected degrees of freedom and corrected $p$ 's will be reported together with $\varepsilon$. Statistical analyses for all measures were accomplished with Statistica 8.

\section{Results}

\subsection{Skin conductance response}

Post hoc comparisons of the main effect of stimulus ( $F(3$, $111)=5.12, p<.01, \varepsilon=.72$, see Table 1$)$ showed that the moderate load evoked a higher SCR than the light load and than the no stimulus control condition. The SCR to the aversive pictures was increased compared to the no stimulus condition, but did not differ from the SCR to either of both loads. Other post hoc comparisons were not significant.

A main effect of block $(F(4,148)=10.4, p<.001, \varepsilon=.81)$ indicated decreasing SCRs over time.

\subsection{EMG startle response}

A main effect of stimulus was observed when probing at $1500 \mathrm{~ms},(F(3,78)=2.82, p<.05, \varepsilon=.98)$, but not when probing at $500 \mathrm{~ms}(F(3,78)=.29, p=.83, \varepsilon=.94)$ following stimulus onset. Further testing of the former effect (see Table 1) showed that both the light load and the pictures resulted in higher startle responses than the 'no stimulus' condition. Startle responses during the moderate load did not differ from the no stimulus condition.

\footnotetext{
2 Importantly, the number of trials in which no startle response was observed did not differ between stimulus types (pictures versus loads). To explore the impact of excluding the non-responders on the results, we ran the EMG startle response analysis with the non-responders included (resulting in $N=38$ ). This analysis showed similar pattern of results than the one in which the non-responders were excluded.
} Results of these analyses are available upon request. 
Table 1

Means (SD) of SCR, startle magnitude, respiratory parameters and subjective ratings during aversive picture viewing, light and moderate resistive breathing and the no stimulus period.

\begin{tabular}{|c|c|c|c|c|}
\hline & Picture & Light load & Moderate load & No stimulus \\
\hline SCR & $.36(.37)_{b c}$ & $.25(.28)_{\mathrm{ab}}$ & $.38(.30)_{c}$ & $.22(.24)_{a}$ \\
\hline \multicolumn{5}{|l|}{ Startle } \\
\hline $500 \mathrm{~ms}$ probe & $50.39(7.65)$ & $50.72(7.47)$ & 50.25 (9.37) & $48.64(9.16)$ \\
\hline $1500 \mathrm{~ms}$ probe & $52.33(8.11)_{b}$ & $52.67(8.03)_{b}$ & $48.97(8.63)_{\mathrm{ab}}$ & $46.03(8.75)_{a}$ \\
\hline$T_{1}$ & $1.62(.39)_{a}$ & $1.98(.49)_{\mathrm{b}}$ & $2.49(.93)_{c}$ & $1.65(.4)_{\mathrm{a}}$ \\
\hline$T_{\mathrm{E}}$ & $2.35(.63)_{a}$ & $2.18(.57)_{b}$ & $1.72(.72)_{\mathrm{c}}$ & $2.37(.61)_{a}$ \\
\hline$V_{\mathrm{T}}$ & $703(175)_{c}$ & $781(236)_{a}$ & $616(314)_{b}$ & $746(207)_{a c}$ \\
\hline$V_{\mathrm{E}}^{\prime}$ & $10,775(2072)_{\mathrm{a}}$ & $11,890(2467)_{a}$ & $8367(2708)_{b}$ & $11,183(1966)_{a}$ \\
\hline $\mathrm{F}_{\mathrm{et}} \mathrm{CO}_{2}$ & $5.36(.48)_{\mathrm{b}}$ & $5.31(.48)_{a b}$ & $5.2(.67)_{\mathrm{a}}$ & $5.33(.44)_{\mathrm{b}}$ \\
\hline Subjective fear & $23.71(18.28)_{a}$ & $18.38(16.78)_{\mathrm{b}}$ & $23.91(18.82)_{a}$ & $15.18(14.42)_{\mathrm{b}}$ \\
\hline Dominance & $3.44(1.14)_{\mathrm{b}}$ & $3.41(1.07)_{\mathrm{b}}$ & $2.46(1.12)_{a}$ & \\
\hline Valence & $3.41(.71)_{c}$ & $2.93(.91)_{b}$ & $4.02(.79)_{\mathrm{a}}$ & \\
\hline Arousal & $2.51(.90)_{b}$ & $2.32(.76)_{b}$ & $3.32(.99)_{a}$ & \\
\hline
\end{tabular}

Note. $\mathrm{SCR}=$ Log transformed skin conductance response; startle = startle blink magnitude $\left(T\right.$-score); $T_{\mathrm{I}}=$ inspiratory time $($ in $\mathrm{s}) ; T_{\mathrm{E}}=$ expiratory time $($ in $\mathrm{s}) ; V_{\mathrm{T}}=$ tidal volume $($ in $\mathrm{ml}$ ); $V_{\mathrm{E}}^{\prime}=$ minute ventilation (in $\mathrm{ml} / \mathrm{min}$ ); $\mathrm{F}_{\mathrm{et}} \mathrm{CO}_{2}=$ fractional end-tidal $\mathrm{CO}_{2}$; higher ratings on dominance, valence and arousal (1-5 scale) indicate more feelings of control, higher unpleasantness and higher arousal, respectively. Different subscripts depict significant differences (Tukey HSD) between conditions $p<.05$.

\subsection{Respiration}

Inspiratory $\left(T_{\mathrm{I}}\right)$ and expiratory time $\left(T_{\mathrm{E}}\right)$. The moderate load was associated with an increased $T_{\mathrm{I}}$ compared to the light load and $T_{\mathrm{I}}$ was increased for both loads compared to the no stimulus and the picture conditions (main effect of stimulus: $F(3,114)=52.96$, $p<.001, \varepsilon=.41$; see Table 1$)$. A similar pattern was observed for $T_{\mathrm{E}}$ (main effect of stimulus: $F(3,114)=67.6, p<.001, \varepsilon=.75$; see Table 1).

Tidal volume $\left(V_{T}\right)$. Tidal volume was significantly reduced during the moderate load compared to every other stimulus condition. Furthermore, $V_{\mathrm{T}}$ was lower during picture viewing than during the light load (main effect of stimulus: $F(3,114)=11.7, p<.001, \varepsilon=.60$; see Table 1$)$.

Minute ventilation $\left(V^{\prime}{ }_{\mathrm{E}}\right)$. Participants breathed with a lower minute ventilation during the moderate load compared to all other stimuli conditions (main effect of stimulus: $F(3,114)=32, p<.001$, $\varepsilon=.59$; see Table 1 ).

$\mathrm{F}_{e t} \mathrm{CO}_{2}$. Fractional end-tidal $\mathrm{CO}_{2}$ was lower during the moderate load than during aversive picture viewing and during the no stimulus condition, but did not differ from the $\mathrm{F}_{\mathrm{et}} \mathrm{CO}_{2}$ during the light $\operatorname{load}(F(3,114)=4.00, p<.01, \varepsilon=.52$; see Table 1$)$.

\subsection{Subjective measures}

Fear scale. The main effects of stimulus $(F(3,117)=13.5, p<.001$, $\varepsilon=.69)$ and of block $(F(14,546)=3.83, p<.001, \varepsilon=.26)$ were both significant, as well as their interaction $(F(42,1638)=1.95, p<.001$, $\varepsilon=.26$; see Table 1$)$. A significant decreasing linear trend in selfreported fear was observed for the light $\operatorname{load}(F(1,39)=5.91, p<.05)$, the moderate load $(F(1,39)=12.79, p<.001)$ and the no stimulus condition $(F(1,39)=6.82, p<.05)$, but not for the pictures $(F(1$, 39) $=0.42$, n.s.).

Participants reported more fear to the pictures than to the light load and the no stimulus condition. Subjective fear in response to the moderate load was equal to fear in response to pictures, but was enhanced relative to the light load and the no stimulus condition.

Dominance, valence and arousal. Participants reported more unpleasantness and lower dominance to the moderate load than to the light load and the most aversive picture; they also rated the most aversive picture as more unpleasant than the light load (main effect of stimulus: for unpleasantness: $F(2,80)=28.18, p<.001$, $\varepsilon=.78$; for dominance: $F(2,80)=19.05, p<.001, \varepsilon=.87$; see Table 1 ). Similarly, they reported more arousal when confronted with the moderate load than with light load or the most aversive pic- ture (main effect of stimulus: $F(2,80)=22.87, p<.001, \varepsilon=.87$; see Table 1).

\section{Discussion}

The present study documents psychophysiological and subjective responses to inspiratory loads and compares these responses with those to aversive IAPS pictures. Compared to other interoceptive stimulations, such as inhalation of $\mathrm{CO}_{2}$-enriched air, the use of resistive loads has a few advantages. First, the on- and offset of the dyspneic stimulus is easier to control with loads than with $\mathrm{CO}_{2}$. Second, in contrast with $\mathrm{CO}_{2}$, the application of loads is not associated with a taste or smell sensations, which in fact is an exteroceptive feature of $\mathrm{CO}_{2}$-inhalation. Third, discrete, short and repeated stimulus applications are very feasible with loads, allowing for fear paradigms that are structurally very similar than the ones used with exteroceptive aversive stimuli.

Generally, results on electrodermal activity parallel those on self-reported fear. A moderate load $\left(1.96 \mathrm{kPal}^{-1} \mathrm{~s}\right)$ presented for only one inspiration, is associated with subjective fear and a phasic sympathetic arousal response, as reflected in an elevated SCR. Subjective fear and SCR to this moderate load are equal to those evoked by an aversive picture presented for $8 \mathrm{~s}$, but higher than those observed during a no stimulus condition or during the application of a light load just above perceptual threshold $\left(0.49 \mathrm{kPa} \mathrm{l}^{-1} \mathrm{~s}\right)$. In contrast to the moderate load and the aversive pictures, the latter stimulus does not evoke subjective fear or an enhanced SCR relative to the no stimulus condition. These results are in line with predictions based on the defense cascade model (Lang et al., 1997), which would predict increasing SCRs with increasing arousal. A new finding is that SCRs also occur when an interoceptive stimulus is presented. Therefore, the generally accepted idea that SCR reflects a response to an external event (Dawson et al., 2007) may be extended to include interoceptive events, although one may argue that the observed SCR to the loads may also be related to the participants knowing that this 'interoceptive event' was externally initiated by the experimenter.

A potentiated startle blink is not observed when an acoustic startle probe is presented $500 \mathrm{~ms}$ after onset of the loads or the pictures, consistent with the idea that sensorimotor gating and attentional processes inhibit startle responding when a prepulse stimulus (load or picture) is applied shortly before a probe. Similar results have been found in a number of studies (Bradley et al., 1993, 2006; Vanman et al., 1996), although other studies demonstrate that affective startle modulation can sometimes be observed also 
at short lead intervals both in phobics (e.g., Globisch et al., 1999) and healthy persons (Volz et al., 2003; Asli et al., 2009). Future studies may further explore PPI with interoceptive prepulses. However, when inspiratory flow resistors are used to this end, a precise timelocking of the startle probe lead interval with inspiratory onset is recommended. A limitation of the present study is the absence of such exact time-locking.

In contrast with the SCR-results, the startle blink-results do not follow the predictions based on the defense cascade model of Lang et al. (1997). When probing $1500 \mathrm{~ms}$ after stimulus onset, this model would predict increased potentiation with more aversive and more arousing background stimuli. This is not observed in the present study when interoceptive stimuli were applied. First, although the light load is rated less unpleasant and evokes less subjective fear than an aversive picture, both stimuli are associated with an equally potentiated startle blink relative to a no stimulus condition when an acoustic probe is presented $1500 \mathrm{~ms}$ after stimulus onset. Moreover, a moderately intense load that is rated as more unpleasant than the aversive pictures is not associated with a potentiated startle blink relative to the no stimulus condition, whereas the aversive pictures are. Finally, although the moderate load evokes more subjective fear, it is rated more unpleasant and more arousing than the light load, the former is not associated with a larger startle blink than the latter.

Breathing against a load requires an increased muscle effort and a strong breathing restriction (i.e., an inspiratory occlusion) may induce a startle blink (Webster et al., 2004). Both processes may affect the startle responsivity to an acoustic probe during a load application. However, we could not find any evidence in our data supporting these explanations. First, we did not observe an increased occurrence of startle blinks during the baseline period prior to the startle probe for the moderate load condition compared to the other stimulus conditions. Also, baseline EMG levels during the moderate load were not elevated relative to baseline EMG levels during any other stimulus condition, excluding the possibility that the $\mathrm{m}$. orbicularis was tonically activated because of the increased effort associated with breathing against a moderate load.

A speculative explanation for the lack of startle potentiation during the moderate load is that interoceptive aversive stimulation may not easily lead to the defensive attentional mode for which fear potentiated startle is characteristic. In other words, when confronted with the moderate load, participants may not have been in the post-encounter phase, but may have entered the circa-strike phase of the defensive continuum. Self-report measures indeed show relatively high fear ratings and SAM-ratings for the moderate loads. Unfortunately, there is no systematic research on how startle responses behave during the circa-strike mode, but findings suggest that startle potentiation is no longer present if one is engaged in a (covertly) action-oriented defensive mode (Lang et al., 1997; Löw et al., 2008). Because heart rate decreases or increases are thought to allow for a distinction between defensive attention (post-encounter phase) and defensive action (circa-strike phase), future studies may want to implement heart rate measures as well.

An alternative explanation may be that fear potentiated startle does simply not occur during interoceptive aversive stimulation, supporting the idea that startle is a reflex primarily dealing with unexpected, potentially dangerous, environmental stimuli. Interestingly, Craig (2003) proposed a model of 'homeostatic' emotions, such as dyspnea, hunger, and visceral pain. These emotions alert the organism of a possible homeostatic threat and, more importantly, would be associated with specific autonomic and behavioral reactions that aim to re-establish the homeostasis. It is conceivable that startling to an external event may not be a hard-wired adaptive response in the context of a homeostatic threat. Yet another, related explanation may be that participants directed sustained attention to the interoceptive aversive event, thereby limiting processing capacities for the acoustic startle probe.

Although the results of the present study are promising and challenging, they need to be replicated and extended to other types of interoceptive aversive stimuli, e.g., balloon distensions in the gastrointestinal tract (Van Oudenhove et al., 2007). To explore the possible role of an interoceptive versus exteroceptive attentional orientation in the (lack of) startle potentiation during interoceptive aversive stimulation, it may be fruitful to add a reaction time task in response to the acoustic startle probes.

In summary, our findings demonstrate that fear potentiated startle does not occur for a moderate inspiratory load that is associated with self-reported fear. Furthermore, mild loads applied for only one single inspiration lead to electrodermal and subjective fear responses comparable with those to IAPS pictures shown for $8 \mathrm{~s}$.

\section{References}

Acheson, D.T., Forsyth, J.P., Prenoveau, J.M., Bouton, M.E., 2007. Interoceptive fear conditioning as a learning model of panic disorder: An experimental evaluation using 20\% $\mathrm{CO}_{2}$-enriched air in a non-clinical sample. Behaviour Research and Therapy 45, 2280-2294.

Asli, O., Kulvedrosten, S., Solbakken, L.E., Flaten, M.A., 2009. Fear potentiated startle at short intervals following conditioned stimulus onset during delay but not trace conditioning. Psychophysiology 46, 880-888.

Beck, J.G., Shipherd, J.C., Zebb, B.J., 1997. How does interoceptive exposure for panic disorder work? An uncontrolled case study. Journal of anxiety disorders 11, 541-556.

Blanchard, R.J., Blanchard, D.C., 1989. Attack and defense in rodents as ethoexperimental models for the study of emotion. Progress in NeuroPsychopharmacology \& Biological Psychiatry 13, 3-14.

Blanchard, D.C., Hynd, A.L., Minke, K.A., Minemoto, T., Blanchard, R.J., 2001. Human defensive behaviors to threat scenarios show parallels to rear- and anxiety-related defense patterns of non-human mammals. Neuroscience and Biobehavioral Reviews 25, 761-770.

Bloch-Salisbury, E., Harver, A., 1994. Effects of detection and classification of resistive and elastic load on endogenous event-related potentials. Journal of Applied Physiology 77, 1246-1255.

Bloch-Salisbury, E., Harver, A., Squires, N.K., 1998. Event-related potentials to inspiratory flow-resistive loads in young adults: Stimulus magnitude effects. Biological Psychology 49, 165-186.

Blumenthal, T.D., Cuthbert, B.N., Filion, D.L., Hackley, S., Lipp, O.V., Van Boxtel, A. 2005. Committee report: guidelines for human startle eyeblink electromyographic studies. Psychophysiology 42, 1-15.

Bouton, M.E., Mineka, S., Barlow, D.H., 2001. A modern learning theory perspective on the etiology of panic disorder. Psychological Bulletin 108, 4-32.

Bradley, M.M., Codispoti, M., Cuthbert, B.N., Lang, P.J., 2001. Emotion and motivation. I. Defensive and appetitive reactions in picture processing. Emotion 1, 276298.

Bradley, M.M., Codispoti, M., Lang, P.J., 2006. A multi-process account of startle modulation during affective perception. Psychophysiology 43, 486-497.

Bradley, M.M., Cuthbert, B.N., Lang, P.J., 1999. Affect and the startle reflex. In Dawson, M.E., McCall Schell, A., Bohmelt, A.H. (Eds.), Startle Modification: Implications for Neuroscience, Cognitive Science, and Clinical Science. Cambridge University Press, New York, NY, pp. 157-186.

Bradley, M.M., Cuthbert, B.N., Lang, P.J., 1993. Pictures as prepulses: attention and emotion in startle modification. Psychophysiology 30, 541-545.

Bradley, M.M., Lang, P.J., 1994. Measuring emotion: the Self-Assessment Manikin (SAM) and the semantic differential. Journal of Experimental Psychiatry \& Behavior Therapy 25, 49-59.

Center for the Study of Emotion and Attention, 1999. The International Affective Picture System [Photographic Slides]. The Center for Research in Psychophysiology, University of Florida, Gainesville, FL.

Cook, E.W., Melamed, B.G., Cuthbert, B.N., McNeil, D.W., Lang, P.J., 1988. Emotional imagery and the differential diagnosis of anxiety. Journal of Consulting and Clinical Psychology 56, 734-740.

Craig, A.D., 2003. Interoception: the sense of the physiological condition of the body. Current Opinion in Neurobiology 13, 500-505.

Craske, M.G., Rowe, M., Lewin, M., Noriega-Dimitri, R., 1997. Interoceptive exposure versus breathing retraining within cognitive-behavioural therapy for panic disorder with agoraphobia. The British journal of clinical psychology 36, 85-99.

Cuthbert, B.N., Lang, P.J., Strauss, C., Drobes, D., Patrick, C.J., Bradley, M.M., 2003. The psychophysiology of anxiety disorder: Fear memory imagery. Psychophysiology 40, 407-422.

Dawson, M.E., Schell, A.M., Filion, D.L., 2007. The electrodermal system. In: Cacioppo, J.T., Tassinary, L., Berntson, G. (Eds.), Handbook of Psychophysiology, 3rd ed. Cambridge University Press, Cambridge, pp. 159-181.

De Clerck, A., Verschuere, B., Crombez, G., De Vlieger, P., 2006. Psychophysiological analysis (PSPHA): a modular script based program for analyzing psychophysiological data. Behavior Research Methods 38, 504-510. 
Esquivel, G., Diaz-Galvis, J., Schruers, K., Berlanga, C., Lara-Munoz, C., Griez, E., 2008. Acute exercise reduces the effects of a $35 \% \mathrm{CO}_{2}$ challenge in patients with panic disorder. Journal of Affective Disorders 107, 217-220.

Fannes, S., Van Diest, I., Meulders, A., De Peuter, S., Vansteenwegen, D., Van den Bergh, O., 2008. To inhale or not to inhale: conditioned avoidance in breathing behavior in an odor-20\% $\mathrm{CO}_{2}$ paradigm. Biological Psychology 78, 87-92.

Fanselow, M.S., 1994. Neural organization of the defensive behavior system responsible for fear. Psychonomic Bulletin \& Review 1, 429-438.

Forsyth, J.P., Eifert, G.H., Thompson, R.N., 1996. Systemic alarms and fear conditioning. II. An experimental methodology using $20 \%$ carbon dioxide as an unconditioned stimulus. Behavior Therapy 27, 391-415.

Globisch, J., Hamm, A.O., Esteves, F., Öhman, A., 1999. Fear appears fast: temporal course of startle reflex potentiation in animal fearful subjects. Psychophysiology $36,66-75$.

Gray, J.A., McNaughton, N., 2000. Fundamentals of the septo-hippocampal system. In: Gray, J.A., McNaughton, N. (Eds.), The Neuropsychology of Anxiety: An Enquiry into the Functions of Septo-hippocampal System, 2nd ed. Oxford University Press, Oxford, pp. 204-232.

Grillon, C., Ameli, R., Woods, S.W., Merikangas, K., Davis, M., 1991. Fear-potentiated startle: effects of anticipatory anxiety on the acoustic blink reflex. Psychophysiology 28, 588-595.

Hamm, A.O., Vaitl, D., 1996. Affective learning: awareness and aversion. Psychophysiology $33,698-710$.

Han, J., Zhu, Y., Li, S., Zhang, J., Cheng, X., Van den Bergh, O., et al., 2008. The language of medically unexplained dyspnea. Chest 133, 961-968.

Hermans, D., Clarysse, J., Baeyens, F., Spruyt, A., 2005. Affect (Version 4.0) [Computer software]. University of Leuven, Belgium. Retrieved from http://www.psy.kuleuven.be/leerpsy/affect4.

Lang, P.J., Bradley, M.M., Cuthbert, B.N., 1997. Motivated attention: affect, activation, and action. In: Lang, P.J., Simons, R.F., Balaban, M.T. (Eds.), Attention and Orienting: Sensory and Motivational Processes. Erlbaum, Hillsdale, NJ, pp. 97-135.

Lang, P.J., Davis, M.D., Öhman, A., 2000. Fear and anxiety: animal models and human cognitive psychophysiology. Journal of Affective Disorders 61, 137-159.

Lavietes, M.H., Sanchez, C.W., Tiersky, L.A., Cherniack, N.S., Natelson, B.H., 2000. Psychological profile and ventilatory response to inspiratory resistive loading. American Journal of Respiratory and Critical Care Medicine 161, 737744.

Livermore, N., Butler, J.E., Sharpe, L., McBain, R.A., Gandevia, S.C., McKenzie, D.K., 2008. Panic attacks and perception of inspiratory resistive loads in chronic obstructive pulmonary disease. American Journal of Respiratory and Critical Care Medicine 178, 7-12.

Löw, A., Lang, P.J., Smith, J.C., Bradley, M.M., 2008. Both predator and prey: emotional arousal in threat and award. Psychological Science 19 (9), 865-873.
Mikels, J.A., Fredrickson, B.L., Larkin, G.R., Lindberg, C.M., Maglio, S.J., Reuter-Lorenz, P.A., 2005. Emotional category data on images from the International Affective Picture System. Behavior Research Methods 37, 626-630.

Neumann, D.L., Waters, A.M., Westbury, H.R., Henry, J., 2008. The use of an unpleasant sound unconditional stimulus in an aversive conditioning procedure with 8- to 11-year-old children. Biological Psychology 79, 337-342.

Sanderson, W.C., Rapee, R.M., Barlow, D.H., 1988. Panic induction via inhalation of $5.5 \% \mathrm{CO}_{2}$ enriched air: a single subject analysis of psychological and physiological effects. Behaviour Research and Therapy 26, 333-335.

Smits, J.A.J., Powers, M.B., Berry, A.C., Otto, M.W., 2007. Translating empirically supported strategies into accessible interventions: the potential utility of exercise for the treatment of panic disorder. Cognitive and Behavioral Practice 14, 364-374.

Van Diest, I., Davenport, P., Van den Bergh, O., Miller, S., Robertson, E., 2005a. Interoceptive fear conditioning to an inspiratory load using $20 \% \mathrm{CO}_{2}$ inhalation as an unconditioned stimulus. Paper presented at the Twelfth Annual Meeting of the International Society for the Advancement of Respiratory Psychophysiology (ISARP). Hamburg, Germany.

Van Diest, I., De Peuter, S., Devriese, S., Wellens, E., Van de Woestijne, K.P., Van den Bergh, O., et al., 2005b. Imagined risk of suffocation as a trigger for hyperventilation. Psychosomatic Medicine 67, 813-819.

Vanman, E.J., Boehmelt, A.H., Dawson, M.E., Schell, A.M., 1996. The varying time course of attentional and affective modulation of the startle eyeblink reflex. Psychophysiology 33, 691-698.

Van Oudenhove, L., Vandenberghe, J., Geeraerts, B., Vos, R., Persoons, P., Demyttenaere, K., Fischler, B., Tack, J., 2007. Relationship between anxiety and gastric sensorimotor function in functional dyspepsia. Psychosomatic Medicine 69, 455-463.

Volz, M., Hamm, A.O., Kirsch, P., Rey, E.-R., 2003. Temporal course of emotional startle modulation in schizophrenia patients. International Journal of Psychophysiology $49,123-137$.

von Leupoldt, A., Seemann, N., Gugleva, T., Dahme, B., 2007. Attentional distraction reduces the affective but not the sensory dimension of perceived dyspnea. Respiratory Medicine 101, 839-844.

von Leupoldt, A., Sommer, T., Kegat, S., Baumann, H.J., Klose, H., Dahme, B., et al., 2008. The unpleasantness of perceived dyspnea is processed in the anterior insula and amygdala. American Journal of Respiratory and Critical Care Medicine 177, 1026-1032.

Webster, K.E., Colrain, I.M., 2000. The relationship between respiratory-related evoked potentials and the perception of inspiratory resistive loads. Psychophysiology 37, 831-841

Webster, K.E., Colrain, I.M., Davenport, P.W., 2004. P300 from inspiratory occlusion reflects orienting but not startle. Biological Psychology 66 (1), 21-23. 